\title{
DE LA PRIVATIZACIÓN A LA CORPORATIZACIÓN NEOLIBERAL: TENDENCIAS RECIENTES DE LAS POLÍTICAS PARA LAS EMPRESAS PÚBLICAS EN EL CASO ARGENTINO (2015-2018) ${ }^{1}$
}

\author{
Manuel Yañez ${ }^{2}$
}

http://dx.doi.org/10.1590/1413-2311.236.86414

\begin{abstract}
RESUMEN
El objetivo de este trabajo es analizar las tendencias recientes de las políticas para las empresas públicas argentinas y su relación con los principios y el proyecto político del neoliberalismo. En este sentido, se presenta una revisión de las políticas de las últimas décadas para el sector y se retoma la noción de corporatización neoliberal como referencia para estudiar el proceso en curso. El argumento desarrollado indica que la continuidad de la titularidad estatal de una empresa no impide la implementación de políticas ligadas con el neoliberalismo. A partir de una aproximación cualitativa, se lleva adelante un análisis de diferentes documentos oficiales y otras fuentes secundarias. Los resultados de este trabajo sugieren una convergencia entre las políticas analizadas y los lineamientos típicos de los procesos de corporatización neoliberal.
\end{abstract}

Palabras clave: Empresas Públicas. Neoliberalismo. Gobierno Corporativo. Política Pública. Argentina.

\footnotetext{
${ }^{1}$ Recebido em 05/09/2018; aprovado em 06/05/2019.

2 Universidad de Buenos Aires - Facultad de Ciencias Económicas, Centro de Investigaciones en Administración Pública y Consejo Nacional de Investigaciones Científicas y Técnicas (CONICET); Buenos Aires (Argentina) - http://orcid.org/0000-0001-8575-516X. E-mail: manuelyanez@economicas.uba.ar.
} 


\title{
DA PRIVATIZAÇÃO À CORPORATIZAÇÃO NEOLIBERAL: TENDÊNCIAS RECENTES EM POLÍTICAS PARA AS EMPRESAS PÚBLICAS NO CASO ARGENTINO (2015-2018)
}

\begin{abstract}
RESUMO
O objetivo deste artigo é analisar as tendências recentes das políticas para empresas públicas argentinas e sua relação com os princípios e ao projeto político do neoliberalismo. Nesse sentido, apresenta-se uma revisão das políticas das últimas décadas para o setor e a noção de corporatização neoliberal é tomada como referência para o estudo do processo atual. O argumento desenvolvido indica que a continuidade da propriedade estatal de uma empresa não impede a implementação de políticas vinculadas ao neoliberalismo. A partir de uma abordagem qualitativa, é realizada uma análise de diferentes documentos oficiais e outras fontes secundárias. Os resultados deste trabalho sugerem uma convergência entre as políticas analisadas e as diretrizes típicas dos processos de corporatização neoliberal.
\end{abstract}

Palavras-Chave: Empresas Públicas. Neoliberalismo. Governo corporativo. Política pública. Argentina.

\section{FROM PRIVATIZATION TO NEOLIBERAL CORPORATIZATION: RECENT TRENDS IN POLICIES FOR PUBLIC ENTERPRISES IN THE ARGENTINE CASE} (2015-2018)

\begin{abstract}
The aim of this paper is to analyze recent trends in policies for Argentine public enterprises and their relationship with the principles and political project of neoliberalism. In this sense, a review of the policies of the last decades for the sector is presented and the notion of neoliberal corporatization is taken up as a reference to study the current process. The argument developed indicates that the continuity of the state ownership of a company does not preclude the implementation of policies linked to neoliberalism. From a qualitative approach, an analysis of different official documents and other secondary sources is carried out. The results of this work suggest a convergence between the policies analyzed and the typical guidelines of neoliberal corporatization processes.
\end{abstract}


Keywords: Public Enterprises. Neoliberalism. Corporate Governance. Public Policy. Argentina.

\section{INTRODUCCIÓN}

A lo largo del siglo XX en América Latina emergieron una serie de entidades y empresas públicas ${ }^{3}$ que tomaron bajo su control las más diversas actividades económicas. Éstas abarcaron áreas relacionadas al despliegue de infraestructura, la producción de bienes en sectores estratégicas y la provisión de servicios públicos (BELINI; ROUGIER, 2008; GUAJARDO; LABRADOR, 2015). Frecuentemente, la acción empresaria estatal buscaba incentivar la industrialización en economías tradicionalmente ligadas a la producción de materias primas (MONTES, 2013; REGALSKY; ROUGIER, 2015). En términos generales, se señalaba al Estado como portador de un rol preponderante para el desarrollo y se consideraba necesaria su intervención para el impulso del crecimiento económico y la mejora del bienestar social (CHAVEZ; TORRES, 2013; SCHCLAREK CURUTCHET, 2013).

Los procesos de reforma estatal latinoamericanos orientados por el neoliberalismo ganaron fuerza durante las décadas de 1980 y 1990, implicando — entre otros aspectos - la reformulación de las funciones del Estado. Esto supuso el debilitamiento del sector de las empresas públicas en la gran mayoría de los países de la región, en el marco del desaliento a la intervención estatal directa en el plano estrictamente económico (VILAS, 1997). Luego, a inicios del siglo XXI, el papel desempeñado por el Estado se ubicó nuevamente en el centro del debate público, en el marco de gobiernos que han sido ocasionalmente bautizados como 'posneoliberales' o 'neodesarrollistas', entre otras denominaciones (BRESSER PEREIRA, 2007; KATZ, 2015; SADER, 2008; STEFANONI, 2012). Entre otros aspectos, estos gobiernos tendieron a impulsar un mayor protagonismo directo y a promover acciones estatales en el ámbito económico, revalorizándose también en ese derrotero el rol de las empresas públicas (CHAVEZ; TORRES, 2013; GUAJARDO SOTO, 2015; THWAITES REY, 2016).

\footnotetext{
${ }^{3}$ En ocasiones, resulta pertinente diferenciar entre el carácter público o estatal de una entidad; por ejemplo, desde una perspectiva que se limita a discurrir entre los atributos de propiedad y control, Florio (2014b) distingue entre las nociones de empresas públicas y empresas de propiedad estatal. Sin embargo, para los fines de este trabajo se toman ambos términos indistintamente.
} 
El panorama internacional de las empresas públicas siguió una trayectoria similar a lo ocurrido en el caso latinoamericano: el sector tuvo un auge durante la segunda posguerra abarcando diversos sectores de la actividad económica - y un declive sobre el final del siglo $\mathrm{XX}$ - en el marco de masivos procesos de privatización - (MILLWARD, 2011; TONINELLI, 2000, 2008). Luego, la crisis económica mundial de 2008 y la creciente presencia internacional de compañías estatales - particularmente, de las originarias de China - dieron cuenta de un cambio respecto a la tendencia anterior, reposicionando a las empresas públicas en el debate político y académico (BERNIER, 2014; CHRISTIANSEN, 2011; ESTRIN et al., 2016; FLORIO, 2014a; VOSZKA, 2017). Desde entonces, se ha revisado el precepto de la superioridad del sector privado respecto al sector público en términos de eficiencia (FLORIO, 2014b; HALL, 2014) y se ha profundizado en las potencialidades y pertinencia de la acción estatal, como sucede en las discusiones en torno del denominado 'Estado emprendedor' (MAZZUCATO, 2011). Además, se han renovado las controversias sobre las formas de propiedad y control público de entidades empresariales (BRUTON et al., 2015; FLORIO, 2013) y sobre las modalidades de prestación de servicios básicos — por ejemplo, en referencia a los denominados procesos de 'remunicipalización' (MCDONALD, 2018; PIGEON et al., 2013).

En este escenario internacional y regional, el gobierno conservador argentino asumido en 2015 no ha explicitado la intención de revertir las nacionalizaciones y creaciones de empresas públicas acaecidas en el período 2003-2015. Durante esos años, el sector empresarial estatal creció en relevancia, cantidad y ámbitos de actuación, lo cual expresó una tendencia contraria respecto al período de auge neoliberal (DIÉGUEZ; VALSANGIACOMO, 2016; PÉREZ; ROCCA, 2017; RE CRESPO; SCHCLAREK CURUTCHET; TORRES, 2011). Aunque las actuales autoridades no han propuesto la implementación de tradicionales programas de privatización, sí se ha avanzado en el establecimiento de una serie de orientaciones de políticas públicas para el sector que - sin modificar en el corto plazo la propiedad formal estatal de las entidades involucradas - esbozan un cambio en la manera de concebir la gestión y el rol de las empresas públicas (JEFATURA DE GABINETE DE MINISTROS, 2017, 2018).

El objetivo del presente trabajo es analizar los lineamientos que orientan las políticas estatales $^{4}$ recientes para las empresas públicas argentinas y su relación con los principios y el

\footnotetext{
${ }^{4}$ Entendemos las políticas estatales —o políticas públicas - en línea a la conocida perspectiva de Oszlak y O’Donnell (1995, p. 112-113) según la cual aquellas se identifican con "un conjunto de acciones y omisiones que manifiestan una determinada modalidad de intervención del estado en relación con una cuestión que concita la atención, interés o movilización de otros actores en la sociedad civil".
} 
proyecto político el neoliberalismo. Con ese fin nos enfocamos en el período 2015-2018, pero asumiendo una estrategia de aproximación que lo inscribe en la trayectoria de las orientaciones de políticas para las empresas públicas implementadas desde fines del siglo XX. Particularmente, se argumenta que la continuidad de la titularidad jurídica estatal de una empresa no imposibilita la implementación de políticas ligadas al neoliberalismo. En este sentido, se considera que los desarrollos en torno a la noción de 'corporatización neoliberal' (MCDONALD, 2015, 2016) pueden brindar algunas guías acerca de la lógica de la orientación de las políticas propuestas en los últimos años en Argentina, así como de sus implicaciones futuras.

Se trata de un trabajo con intenciones exploratorias y parcialmente descriptivo en torno al caso analizado, dado el incipiente desarrollo de esta temática particular. Aunque más no sea en términos preliminares, el análisis de las tendencias de las políticas estatales para el sector de las empresas públicas argentinas asume la potencialidad de configurarse en un 'caso crítico' (FLYVBJERG, 2004) en el contexto latinoamericano, en vistas de la posibilidad de que asuma una importancia estratégica para la reflexión sobre el problema general. La indagación se basa en un enfoque fundamentalmente cualitativo, apoyado en el análisis de diferentes informes y documentos oficiales, así como de otras fuentes secundarias (VALLES, 1997).

Este trabajo está organizado, además de la presente introducción y las consideraciones finales, en tres apartados. Primero, se presentan algunos antecedentes y definiciones sobre el neoliberalismo y las políticas de privatización de empresas públicas realizadas bajo su influencia. Segundo, se trazan las características principales del paradigma de la Nueva Gestión Pública en el marco de las políticas de reforma estatal, al tiempo que se delimita el concepto de 'corporatización neoliberal', particularmente pertinente para caracterizar determinados procesos de mercantilización entidades públicas. Tercero, se exponen los principales lineamientos de las políticas estatales recientes para el sector de las empresas públicas de Argentina, en el marco de sus conexiones con los principios neoliberales. Por último, se presentan algunas reflexiones del recorrido propuesto, con énfasis en la sistematización de las características asimilables a los procesos de corporatización neoliberal presentes en el caso argentino reciente. Adicionalmente, se esbozan las posibles implicancias para la política pública y algunos interrogantes plausibles de ser retomados en el futuro. 


\section{NEOLIBERALISMO Y PRIVATIZACIÓN DE EMPRESAS PÚBLICAS}

\subsection{NEOLIBERALISMO Y REFORMAS ESTATALES EN AMÉRICA LATINA}

Los señalamientos críticos a la acción estatal que emergieron con fuerza durante la década de 1980 en América Latina se apoyaron, por un lado, en un diagnóstico negativo de lo que había sido el previo avance de la intervención del Estado en los diversos ámbitos de la vida social; y por otro, en una reivindicación del mercado como el mejor principio ordenador de la sociedad (LECHNER, 1992; VILAS, 1991, 1997). En este marco, el ajuste estructural emergió como solución a la crisis fiscal y el débil desempeño estatal, al tiempo que las políticas de liberalización, desregulación y privatización inspiradas en el denominado “Consenso de Washington” se pusieron a la orden del día (BRESSER PEREIRA, 2007; CASTAÑEDA RODRÍGUEZ; DÍAZ BAUTISTA, 2017).

Esas transformaciones fueron expresión del ascenso más general del neoliberalismo, definido por Harvey (2007, p. 6) como “una teoría de prácticas político-económicas que se apoya en el principio según el cual el bienestar humano se logra a partir de la no restricción de las capacidades y de las libertades empresariales". En un contexto signado por la preeminencia de los derechos de propiedad, el libre mercado y la libertad de comercio, se postula que la acción del Estado debe limitarse a asegurar el marco institucional para que esas prácticas puedan desarrollarse $\mathrm{y}$, en todo caso, favorecer la creación de mercados en áreas donde éstos no existen - como puede suceder en relación con la tierra, el agua, la educación o la seguridad social.

Perry Anderson (2003) señala que, para los ideólogos del neoliberalismo de la década de 1970 y en el marco de la denominada 'crisis del petróleo', estaba claro que las causas de las dificultades económicas y fiscales se encontraban en el poder obtenido a lo largo del siglo XX por parte del movimiento obrero, el cual le otorgaba la capacidad de mantener altos salarios y propiciaba el aumento incesante de los gastos sociales erogados por el Estado. Por consiguiente, la solución propuesta por los propagandistas del neoliberalismo hacía hincapié en la articulación de un Estado especialmente fuerte para mantener bajo control las presiones reivindicativas de los sindicatos, al tiempo que disminuía a su mínima expresión los gastos sociales y la intervención estatal en el plano estrictamente económico.

Desde una perspectiva más general, Duményl y Lévi (2006) presentan al neoliberalismo como una etapa del capitalismo que se caracteriza por el reforzamiento del poder y de la ganancia capitalista. Los autores puntualizan cómo la fracción superior de la 
clase dominante toman protagonismo a partir de dos modalidades institucionales del mencionado empoderamiento: el Estado y las instituciones financieras. Precisamente, una de las expresiones de la reconfiguración de la economía mundial bajo la égida del neoliberalismo está dada por lo que Chesnais (2001) - entre otros — denominan 'mundialización financiera'. Ésta designa las íntimas relaciones entre los sistemas monetarios y los mercados financieros nacionales que surgieron a partir de las políticas de liberalización y desregulación adoptadas inicialmente por los Estados Unidos y el Reino Unido entre 1979 y 1982, luego replicadas en otros países. Esta liberalización externa de los sistemas anteriormente cerrados habilitó la generación de un espacio financiero mundial que, sin embargo, no suprimió los sistemas financieros nacionales, sino que los integró de manera imperfecta.

Durante la década de 1990, el neoliberalismo fue asumido de manera definitiva en la gran mayoría de los países del mundo como la guía fundamental de las políticas estatales ${ }^{5}$. La caída del Muro de Berlín y la desintegración de la Unión Soviética supuso la base para la entronización definitiva de la economía de mercado y la democracia liberal; al tiempo que el avance neoliberal no solo arrasó "con muchas de las conquistas materiales obtenidas por las clases populares durante los años de posguerra sino que también impactaron negativamente en las formas de construcción política e ideológica de los sectores subalternos" (THWAITES REY, 2010, p. 26). Por lo demás, no debe dejar de remarcarse con Harvey (2007, p. 24) que:

[...] la neoliberalización puede ser interpretada bien como un proyecto utópico con la finalidad de realizar un diseño teórico para la reorganización del capitalismo internacional, o bien como un proyecto político para restablecer las condiciones para la acumulación del capital y restaurar el poder de las elites económicas.

Pero la primacía entre estos dos aspectos se encuentra en el último de ellos, ya que el neoliberalismo como discurso legitimador se ha puesto en función de alcanzar su objetivo

\footnotetext{
5 En vistas a esbozar cierta periodización, Perry Anderson (2003) plantea que han existido tres ciclos neoliberales a nivel global. El primero se identifica con el desarrollo centrado en los países del capitalismo "avanzado", en la estela de las políticas impulsadas por los gobiernos de Reagan en Estados Unidos y Thatcher en Gran Bretaña. El segundo se ligó al avance que hizo eje especialmente en los países que antiguamente provenían del denominado socialismo real y que se preparaban para iniciar su entrada de lleno al capitalismo. Por último, el ciclo que se desarrolló en el escenario latinoamericano de los años noventa del siglo pasado. Sin embargo, más allá de lo señalado por el autor, no deja de ser relevante la existencia de algunos antecedentes de "experiencias neoliberales", más o menos integrales, acaecidas en América Latina con anterioridad a los noventa, como los casos de Bolivia en los de los ochenta y de Chile en los setenta. Además, no está de más señalar que las dictaduras militares que proliferaron en la región desde la década de 1970 en muchos casos desarrollaron determinadas políticas que se inspiraban en el paradigma neoliberal.
} 
como proyecto político siempre que las circunstancias así lo dictasen. Esto se expresa también en que, cuando existen contradicciones entre los principios neoliberales y la necesidad de revalidar el poder de las clases dominantes, aquellos son dejados de lado o se reformulan hasta que resultan funcionales. Sin desconocer el peso de las doctrinas y del pensamiento en los procesos políticos y sociales, este énfasis señala "una tensión creativa entre el poder de las ideas neoliberales y las prácticas reales de la neoliberalización que han transformado el modo en que el capitalismo global ha venido funcionando durante las últimas tres décadas" (HARVEY, 2007, p. 26).

\subsection{LAS POLÍTICAS DE PRIVATIZACIÓN: APROXIMACIONES CRÍTICAS Y ARGUMENTOS NEOLIBERALES}

En lo que respecta a las políticas de privatización, las mismas se pueden conceptualizar inicialmente como el traspaso al sector privado de una determinada actividad u organismo anteriormente de titularidad y/o bajo control estatal. En este marco, desde una perspectiva crítica las políticas de privatización se pueden leer como la decisión de trasferir al proceso de acumulación capitalista determinadas funciones anteriormente desempeñadas por el Estado, lo que supone una mercantilización de relaciones sociales anteriormente estatalizadas (BONNET, 2007).

Por su parte, Harvey (2005) interpreta los procesos de privatización en el marco de su análisis de los denominados ajustes espacio-temporales ${ }^{6}$; particularmente, explica esos procesos a partir del desarrollo de la noción de 'acumulación por desposesión'. Esta idea engloba diversos procesos que tienden a favorecer una serie de modalidades de despojo económico, relacionados con lo que en Marx se vincula al fenómeno de la acumulación originaria. Aquí se incluyen diversos tipos de procesos como la privatización y

\footnotetext{
${ }^{6}$ Los ajustes espacio-temporales son considerados por el Harvey como la manera que ha tenido el capitalismo para superar su tendencia recurrente a generar crisis de sobreacumulación en diferentes momentos de su historia. Dichas crisis se manifiestan, por un lado, en excedentes de capital, expresados en sobreabundancias de mercancías que no pueden venderse sin pérdidas, en capacidades productivas inutilizadas y/o excedentes de capital-dinero que no sin oportunidades de inversión rentable; y por otro, en excedente de fuerza de trabajo, expresado en creciente desempleo. En definitiva, se origina una situación en la cual dichos excedentes no pueden realizarse ni cumplir una tarea socialmente útil en un sistema territorial determinado. El ajuste espaciotemporal implica la reabsorción de estos excedentes mediante determinados procedimientos: el desplazamiento temporal, mediante de la implementación de proyectos de inversión de capital a largo plazo o en gastos sociales, que difieren hacia el futuro los excedentes; el desplazamiento espacial, el cual implica la apertura de nuevos mercados, la puesta en marcha de nuevas capacidades productivas y la aparición de nuevas posibilidades de recursos y de trabajo en otros territorios; o alguna combinación de las dos opciones anteriores. Sobre esta perspectiva, véase Harvey (2005).
} 
mercantilización de tierras; la transformación de derechos de propiedad comunes, colectivos o estatales en derechos de propiedad exclusivos; la supresión del derecho a los bienes comunes; las políticas coloniales e imperiales de apropiación de recursos naturales; y la deuda pública y el sistema de crédito, entre otros. En todos estos procesos, el Estado cumple un rol fundamental, en tanto impone su monopolio de violencia y legalidad para darles impulso. En la actualidad, estas dinámicas no son ajenas al desarrollo capitalista; además, señala Harvey, se suman nuevos mecanismos, como la imposición de derechos de propiedad intelectual sobre productos de la naturaleza - como materiales genéticos o semillas - y la mercantilización de los denominados "bienes comunes"7. En este marco, "[1] a vuelta al dominio privado de derechos de propiedad común ganados a través de la lucha de clases del pasado (el derecho a una pensión estatal, al bienestar, o al sistema de salud nacional) ha sido una de las políticas de desposesión más egregias llevadas a cabo en nombre de la ortodoxia neoliberal" (2005, p. 115). En esta línea es que las privatizaciones realizadas bajo el auspicio neoliberal pueden interpretarse como uno de los mecanismos de desposesión más característicos de las políticas estatales.

Ahora, ¿cómo se han fundamentado las políticas de privatización por parte de sus promotores? Devlin (1993) presenta una buena síntesis de las razones esgrimidas por los impulsores de la privatización de empresas públicas en América Latina a partir de identificar una serie de factores estructurales que las incentivaron: (a) 'ideología' - a partir de la idea neoliberal de un "Estado subsidiario" que solo asuma las actividades que el sector privado no puede o no quiera realizar; (b) 'eficiencia interna' - en general ligadas a teorías económicas que pregonan la mayor eficiencia del sector privado frente al público; (c) 'cambios en los sectores considerados estratégicos' - la liberalización y aumento de competitividad, sumado a los cambios tecnológicos y administrativos, habrían puesto en cuestión la necesidad de contar con empresas productivas estatales; (d) 'reubicación del sector privado' - existiría una revitalización del sector privado, lo cual hace innecesario el impulso estatal al desarrollo de determinados sectores productivos; (e) 'la necesidad percibida de proyectar coherencia' siendo que se apuntaba a un modelo en el que predomine el sector privado, la persistencia de empresas públicas en sectores competitivos puede generar ciertos grados de conflicto.

\footnotetext{
${ }^{7}$ Aunque excede el marco de este trabajo, la cuestión de los bienes comunes — commons, según la expresión en inglés - se puede abordar desde diferentes enfoques, en algunas ocasiones potencialmente compatibles con el paradigma neoliberal y en otras decididamente críticos con éste. Sobre la cuestión de los bienes comunes desde diversas perspectivas, por ejemplo véase: Ostrom (2010); Jiménez Martín y Puello-Socarrás (2017); Bakker (2007); McCarthy (2005).
} 
En torno a los aportes de la teoría económica que han dado sustento a las políticas de privatización, sobresalen aquellos argumentos que sostienen como principio que una misma empresa es más eficiente en manos del sector privado que en el sector público. En general, se parte de poner en foco la cuestión de los denominados 'costos de transacción', definidos como las características o dimensiones de una transacción que hacen que el intercambio de bienes y servicios sea problemático o importe determinado costo. En ese marco, la efíciencia se sitúa como la manera de medir el desempeño, entendido como la forma de economizar dichos costos (SALGADO, 2003).

Por su parte, la denominada 'teoría de la agencia' postula que los objetivos de principales (propietarios) y agentes (gestores) no son siempre compatibles entre sí: en términos generales, apuntan a la maximización de beneficios en el primer caso y de su remuneración en el segundo. Por lo tanto, los mecanismos de supervisión y los problemas originados en el desvío de los resultados buscados por los principales suponen determinados costos adicionales, que son llamados ocasionalmente 'costos de agencia'. En el caso particular de las empresas públicas, emergen aspectos específicos que incidirían en una menor eficiencia respecto a la empresa privada, a saber: la existencia de dos principales (el gobierno y los ciudadanos) que no siempre tienen el mismo objetivo; la presencia de objetivos políticos o de bienestar y no solo en torno a la obtención de beneficios; la ausencia de control externo por parte de los mercados; la falta de incentivos en las empresas públicas; debilidades en la dirección por falta de profesionalismo, originado en la selección de personal basados en criterios políticos o de lealtad; y la existencia de procedimientos administrativos complejos, propios del sector público (HERNÁNDEZ DE COS, 2004; VICHER, 2010).

Finalmente, la 'teoría de la elección pública' — 'public choice' — sostiene que las empresas públicas se configuran como otra manera que tienen los políticos de satisfacer sus intereses. Los objetivos según esta mirada se ubican en: a) obtener rentas en su beneficio, como otra forma de burocracia, extrayendo ganancias mediante diversas maneras ligadas a formas de corrupción (como discrecionalidad en las compras, designación de familiares y/o ventas en términos beneficiosos a allegados); o b) ganar el apoyo de los electores, distribuyendo rentas de diversas maneras tales como el ofrecimiento de puestos laborales y de niveles salariales de manera excesiva, sobreinversión y pago de precios altos a proveedores para ampliar el apoyo político, sostenimiento de bajos precios para determinados usuarios y/o cobertura excesiva de servicios en relación a la demanda (FLORIO, 2014b).

En definitiva, este conjunto de argumentos económicos apunta a posicionar a la privatización como la mejor política para acrecentar el bienestar social y el crecimiento 
económico. En algunos casos, se sostiene la posibilidad de regulación pública para mitigar determinados efectos negativos, pero esto no debilita la propensión a postular la implicación del sector privado como forma de mejorar los niveles de eficiencia y bienestar.

\section{NUEVA GESTIÓN PÚBLICA Y CORPORATIZACIÓN DE EMPRESAS}

\subsection{LOS REAJUSTES DEL NEOLIBERALISMO Y LA NUEVA GESTIÓN PÚBLICA}

Un momento particular de las reformas estatales en América Latina estuvo dado por lo que en ocasiones ha sido denominado como el período de 'aggiornamiento neoliberal' (EZCURRA, 1998), ocasión en que los impulsores de las reformas dieron un giro relativo a partir de pregonar la necesidad de mejorar el desempeño de las instituciones con miras a perfeccionar el funcionamiento de los mercados (FLEURY, 1999; PRATS I CATALÁ, 1999; VILAS, 2000). En ese marco, se intensificó el énfasis en los cambios administrativos del aparato estatal como medio para aumentar su eficiencia y eficacia, lo cual reforzó la orientación de las reformas en torno a los principales lineamientos del paradigma de la Nueva Gestión Pública (NGP) - new public management, según la expresión en inglés — (LÓPEZ, 2002; ZURBRIGGEN, 2007).

Tomado como un fenómeno único, pero no unívoco, el paradigma de la NGP se convirtió desde fines de los años setenta en el centro de la doctrina oficial sobre la reforma administrativa en gran parte de los países desarrollados (HOOD, 1991). Sin embargo, no se debe desestimar la existencia de diferentes matices al interior de ese paradigma y, más aún, se corroboran experiencias prácticas divergentes respecto al modelo de la NGP en los países que lo tomaron como referencia para sus procesos de reformas (POLLITT; BOUCKAERT, 2011).

De manera sintética, se puede afirmar que la NGP apunta al establecimiento de un sector público con propensión a la descentralización - en contraste con la jerarquía propia de las organizaciones administrativas tradicionales - y con énfasis en el aumento del desempeño y los resultados de las organizaciones públicas. Según Guerrero (2004), mientras la primera etapa del proceso de reforma supuso una 'exoprivatización', entendida como el proceso mediante el cual la administración pública transfiere la producción de bienes y servicios a empresas y entes privados, esta segunda etapa - identificada en gran medida con la NGP - se corresponde con una 'endoprivatización', la cual implica el reemplazo de la 
gestión de los asuntos públicos por las ideas, metodologías y técnicas propias del espíritu empresarial privado.

En este marco, las reformas de la NGP comprenden una serie de medidas que hacen eje en:

[...] la gestión por encima de las políticas; en organizar el gobierno en grupos de agencias y de departamentos, más que en pirámides tradicionales y jerarquizadas; en la adopción de toma de decisiones estratégicas y orientadas a la obtención de resultados, utilizar objetivos de output, indicadores del rendimiento, pagos en relación con los resultados y medidas de mejora de la calidad; en recortar los gastos en vez de crear nuevos; en una mayor flexibilidad; en una mejora de la eficiencia en la prestación de servicios públicos; en la promoción de la competencia en el ámbito y entre organizaciones del sector público (SULEIMAN, 2011, p. 6).

En ocasiones, esta perspectiva vuelve a ubicar en el centro del debate la tradicional dicotomía entre la racionalidad sustantiva de la esfera política y la racionalidad instrumentalformal de la gestión: el resultado es la tendencia al aislamiento de la administración respecto a la política y a la reivindicación de la administración como origen de instrumentos de gestión pretendidamente universales (BLUTMAN; CAO, 2012). Las grandes discusiones políticas — como las relativas a las funciones estatales - tienden a ubicarse fuera del debate público, restringiendo las posibles controversias a temas técnicos y procedimentales (VILAS, 2009).

En cuanto a sus orígenes teóricos, Hood (1991) caracteriza a la NGP como la convergencia de dos corrientes de pensamiento que aparecen, en ocasiones, contradictorias entre sí. Por un lado, la aproximación proveniente de la denominada nueva economía institucional, basada en las teorías de la elección pública, de los costos de transacción y del principal-agente - las cuales hemos desarrollado brevemente en el apartado anterior. Por otro, la perspectiva del 'gerencialismo' — managerialism, según la expresión en inglés — en el sector público, la cual parte de las ideas de la superioridad de la gestión profesional y el conocimiento experto ante otros elementos o consideraciones de tipo político; se postula, por lo tanto, la necesidad de dotar de discrecionalidad y autonomía gerencial a las organizaciones como forma de mejorar sus resultados.

La perspectiva de la 'agencialización' resulta uno de los ejes principales de las reformas propuestas por la NGP, aunque en la práctica puede hallarse en diferentes 
tradiciones y contextos administrativos (MOYNIHAN, 2006). Las entidades creadas bajo este movimiento presentan en la práctica diversos grados de autonomía (de gestión, financiera, sobre el personal, en la implementación de políticas), una gran variedad de áreas de actividad y diferentes estatus jurídicos, entre otros aspectos (DAN et al., 2012; VAN THIEL, 2012).

En cualquier caso, pueden mencionarse al menos tres características básicas de las agencias basadas en la NGP: (a) disgregación estructural y/o la creación de organizaciones con propósitos específicos; (b) existencia de un contrato de resultados, o al menos el establecimiento de ciertos mecanismos de fijación, monitoreo y reporte de los resultados esperados; y (c) desregulación (o adopción de una regulación apropiada) sobre el control del personal, las finanzas y otros asuntos de gestión (MOYNIHAN, 2006).

Guerrero (2009) destaca, por un lado, la íntima ligazón de la NGP con el neoliberalismo, en tanto éste le ha brindado un cuerpo doctrinario sobre el cual aquella ha podido desarrollarse. En este sentido, la NGP es la expresión más clara del neoliberalismo en la administración pública. Por otro, el autor mexicano señala que los resultados frecuentemente negativos que han evidenciado las políticas de la NGP han supuesto una crisis que, agregamos, está lejos de haber desembocado en un nuevo paradigma claramente identificable. Así es que una parte importante de las aproximaciones relativamente críticas a la NGP han tendido a limitarse a señalar determinados aspectos considerados negativos por ejemplo, en torno al déficit de coordinación entre organismos estatales - y a proponer acciones que complementen o mejoren sus resultados, sin llegar a realizarle cuestionamientos de fondo (CHRISTENSEN; LÆGREID, 2011).

Partiendo de considerar la relación entre la NGP y el paradigma neoliberal, se hace aún más patente uno de los aspectos más significativos del neoliberalismo: éste no se trata de un fenómeno estático y monocorde, sino que es esencialmente dinámico y altamente adaptativo. Como señala Puello-Socarrás (2015, p. 27), el neoliberalismo destaca por su resiliencia, entendida como "la capacidad de una entidad para resistir los desafíos críticos (en este caso en particular, la crisis ideológica y epistémica) y renovarse o recomponerse”. Esta característica le ha permitido sostener el núcleo de sus objetivos político-económicos desde una posición hegemónica incluso hasta nuestros días, más allá de sus diferentes reformulaciones y de las medidas concretas que impulse en diferentes momentos históricos. 


\subsection{LA CORPORATIZACIÓN NEOLIBERAL DE EMPRESAS PÚBLICAS}

La noción de 'corporatización' se relaciona con los principios de los procesos de agencialización típicos de la NGP, aunque no en todos los casos concretos siguen los lineamientos señalados. En su aproximación a esta temática, McDonald (2015) parte de considerar algunas características generales que asume lo público en los procesos de corporatización para luego precisar algunos elementos que, por lo demás, revisten especial importancia para nuestra indagación sobre la cuestión de las empresas públicas. En este marco, el autor canadiense parte de señalar que "[1] as entidades corporatizadas, en ocasiones llamadas 'agencias' o 'paraestatales', son de propiedad y gestión totalmente estatales, pero cuentan con cierto grado de autonomía del Gobierno. Por lo general, tienen un régimen jurídico separado de otros proveedores públicos y una estructura corporativa parecida a las compañías privadas que cotizan en bolsa, como un consejo de administración” (p. 9).

Como el propio McDonald señala, el caso de las empresas estatales es la forma más común que estos procesos adoptan al implicar la prestación de servicios públicos y, eventualmente, la provisión de diversos bienes económicos. En cualquier caso, el objetivo de este tipo de procesos es el de crear compañías de plena competencia, con gerentes independientes con responsabilidad sobre su propia organización y donde los gastos e ingresos se contabilizan de manera autónoma respecto al resto del sector público. A partir de esta compartimentalización se apunta a mejorar la transparencia, la rendición de cuentas y evitar injerencias políticas. En muchos casos, el avance de la corporatización viene de la mano del desarrollo de perspectivas ideológicas favorables al mercado y tendientes a adoptar diversos métodos y formas propios del sector privado en el público. Además, frecuentemente se considera la corporatización como el primer paso previo a avanzar en políticas de privatización, luego de que la entidad en cuestión alcance el máximo nivel de beneficios y se ajuste en el mayor grado posible a las condiciones propias del mercado.

En ocasiones, se ha considerado el impulso dado a la corporatización como parte de un cambio de estrategia bajo el paradigma del neoliberalismo, ante la pérdida de legitimidad de los procesos de privatización clásicos de las décadas previas (MAGDAHL, 2012). Sin embargo, McDonald (2015) los diferencia e incluso señala que existe más de una forma en que la corporatización se puede presentar en la práctica. La más relevante para nuestro análisis es la que denomina la 'empresa corporatizada neoliberal', a la que se señala como la forma predominante, siendo minoría los casos de 'corporatización progresista'. Bajo esta última categoría el autor incluye la formación de entidades con una estructura administrativa 
similar a la entidad corporatizada típica - lo que implica su encuadre bajo un régimen jurídico distinto al del resto del sector público y que cuenta con cierta autonomía operacional y financiera -, pero con el resultado de una mejora en la calidad y el acceso del servicio prestado. En estos casos, el énfasis se aleja de la mirada de la mercantilización y la recuperación de los costos, para privilegiar otros objetivos de tipo público o social. En determinadas situaciones, inicialmente la corporatización puede verse incluso como una alternativa a la privatización tradicional, pero dependerá de las modalidades que adopte en la práctica para evaluar realmente el alcance de esas diferencias ${ }^{8}$.

Por su parte, la corporatización neoliberal puede considerarse como parte del más amplio movimiento enmarcado en el paradigma de la NGP y es posible concebirla como una deliberada intervención estatal destinada a introducir paulatinamente determinados aspectos ideológicos ligados al mercado en el ámbito de los servicios públicos. Además, cumple la función de atacar lo que son percibidas como errores legados por el anterior predominio del intervencionismo keynesiano, con sus subsidios estatales ocultos que distorsionan las señales del mercado y sus procedimientos burocráticos represivos que ahogan la habilidad del Estado de dar respuesta a los movimientos mercantiles (MCDONALD, 2016).

En el caso de la corporatización neoliberal, el objetivo se centra en el rendimiento monetario de la entidad en cuestión, para lo que se vale de diferentes modalidades que tienden a afianzar un proceso de 'mercantilización'. En esta línea, la propensión a fijar salarios altos para los directivos — así como incentivos monetarios según el desempeño"propicia muchas veces un cambio en la vocación gerencial, que pasa a centrarse en los balances financieros a corto plazo, creando entidades de propiedad y gestión estatal que se comportan como compañías privadas, imitando el discurso y las prácticas empresariales del sector privado, y estableciendo sistemas de competencia que pueden servir para 'vaciar' el Estado" (MCDONALD, 2015, p. 26).

En la práctica, en esta perspectiva se busca mejorar los ingresos mediante el precepto de que los precios deben reflejar los costos, al tiempo que se bajan los gastos mediante diversas formas de externalización y recorte presupuestario. En estos casos, la titularidad estatal de una empresa se corresponde con la comprensión de sus potencialidades para repercutir favorablemente en la acumulación de capital privado sin las desventajas —en términos de conflictos sociales o políticos- que los procesos de privatización pueden traer aparejados.

\footnotetext{
${ }^{8}$ En relación a las experiencias de corporatización progresista, véanse por ejemplo los distintos casos presentados en McDonald y Ruiters (2013) y McDonald (2015).
} 
Este tipo de corporatización profundiza los problemas de coordinación y la falta de una economía de escala típicos de las entidades compartimentalizadas. Esta "miopía" de la corporatización neoliberal se basa en un énfasis en los resultados financieros y en el establecimiento de formas monetizadas de evaluación de desempeño, aun cuando esos objetivos sean a costa del desempeño del resto de las entidades públicas o del interés público. En este caso, la eliminación de subsidios cruzados se vuelve una prioridad, incluso cuando eso atente contra el acceso a los servicios públicos por parte de sectores socioeconómicamente vulnerables. Asimismo, la prioridad dada a los resultados financieros pone a la orden del día una tendencia creciente hacia la mercantilización de los bienes y los servicios provistos por la entidad corporatizada y la creciente adopción de precios de mercado. En este escenario, se troca el carácter de ciudadano por el de consumidor de un servicio o bien, disociando su acceso del contexto y distanciándolo de cualquier tipo de derecho social que pueda atribuírsele (MCDONALD, 2016).

Recapitulando lo señalado hasta aquí, podemos sintetizar los aspectos que permiten caracterizar la corporatización neoliberal en el ámbito de las empresas públicas a partir de los siguientes elementos: compartimentalización respecto al resto de la administración pública, con cierta tendencia a acrecentar la autonomía de los directivos en el manejo de la entidad; profesionalización a partir de una reivindicación de determinado saber técnico que se referencia en el sector privado, al mismo tiempo que se propone la limitación de la injerencia de las autoridades políticas; ampliación de ámbitos y lógicas mercantiles, tanto en las modalidades de gestión interna como en la relación con otros actores y el mercado en general; y evaluación de la eficiencia a partir del resultado financiero, limitando las consideraciones relativas a los objetivos sociales y de política pública que estén involucrados.

Por lo demás, esta perspectiva puede resultar especialmente pertinente para nuestra indagación en tanto considera a la corporatización como un proceso que puede adoptar distintos grados y diferentes direcciones. De esta manera, se habilita el análisis de la trayectoria de una misma empresa o conjunto de empresas teniendo en cuenta las tendencias en su gestión y desempeño, más allá de la continuidad de la propiedad pública sobre la entidad analizada. Particularmente, si nos remitimos al caso de las empresas públicas argentinas, permite reflexionar sobre la existencia de determinados elementos en las políticas públicas para el sector que pueden permitan describir tendencias hacia la profundización (o no) en un sentido neoliberal. 


\section{TENDENCIAS RECIENTES DE LAS POLÍticas ESTATALES PARA LAS EMPRESAS PÚBLICAS EN ARGENTINA}

\subsection{ANTECEDENTES Y CAMBIOS RECIENTES EN EL SECTOR DE LAS EMPRESAS PÚBLICAS ARGENTINAS}

El proceso de reforma del Estado en Argentina de inicios de la década de 1990 no desentonó del panorama internacional y regional de la época, centrando sus acciones en torno a cuatro ejes: modificaciones en el papel del Estado, búsqueda de estabilidad económica, reestructuración del aparato institucional y reformulación de la política de recursos humanos en el ámbito público (BLUTMAN, 2013). Entre las políticas más significativas se destacó la referida a la privatización de empresas y servicios públicos: durante el período, más de sesenta empresas públicas nacionales fueron traspasadas del control estatal al privado (ARZA, 2002; AZPIAZU; BASUALDO, 2004). En ese marco, se instituyeron diversos dispositivos de tercerización y concesión de servicios públicos (THWAITES REY, 2003; THWAITES REY; LÓPEZ, 2005) y se cedieron importantes entidades económicas al dominio privado, legando para el sector público un rol regulador o secundario (OSZLAK, 1999, 2003).

La profunda crisis económica y política argentina desatada en torno a 2001 implicó un quiebre en las tendencias existentes a nivel estatal, modificándose las relaciones entre Estado y mercado en algunos de sus aspectos más significativos (BONNET; PIVA, 2013; SIDICARO, 2003; THWAITES REY, 2010). Estos procesos supusieron, en el caso de los servicios públicos, un procedimiento de renegociación de los contratos de concesión con diferentes resultados y consecuencias (AZPIAZU; SCHORR, 2003). Al mismo tiempo, se manifestó una reversión parcial de la tendencia respecto a las empresas públicas, produciéndose un paulatino aumento del sector hasta alcanzar un total de más de cincuenta entidades para el año 2016 (DIÉGUEZ; VALSANGIACOMO, 2016; PÉREZ; ROCCA, 2017; RE CRESPO; SCHCLAREK CURUTCHET; TORRES, 2011). En la actualidad las actividades de las empresas públicas dependientes del Estado nacional abordan una gran diversidad de actividades económicas, tales como el transporte, la energía, las comunicaciones, el suministro de agua y cloacas, la intermediación financiera y la industria.

Entre las entidades renacionalizadas o creadas desde 2003 con mayor impacto económico-social se puede mencionar la empresa Agua y Saneamientos Argentinos S.A., creada en 2006 para asumir el servicio de provisión de agua potable anteriormente 
concesionado en el área metropolitana de Buenos Aires y una de las entidades dedicadas a esta actividad con mayor cantidad de usuarios a nivel mundial (AZPIAZU; CASTRO, 2013; ROCCA, 2012). En el rubro del trasporte, sobresalen la reestatización de Aerolíneas Argentinas en 2008, principal empresa del sector aerocomercial; y el paulatino regreso al sector público de las empresas ferroviarias concesionadas durante los años noventa, proceso que concluyó en 2015 con la creación de Ferrocarriles Argentinos S.E. (PÉREZ, 2016). Además, en el sector energético vale la pena mencionar el retorno al control estatal de YPF S.A., una las empresas más importantes del país en términos económicos, con un papel protagónico en la industria hidrocarburífera argentina (SABBATELLA, 2012).

Desde fines de 2015, la política del nuevo gobierno conservador supuso algunas continuidades y una serie de cambios significativos en lo que se refiere a la consideración del rol del Estado, recuperando ciertas perspectivas emparentadas con el neoliberalismo (FÉLIZ, 2016). De manera destacada, desde un primer momento la nueva administración se propuso encarar el reordenamiento y reformulación de las políticas para las empresas públicas dependientes del Estado nacional.

En un documento preliminar emitido por la Jefatura de Gabinetes de Ministro (2017) se presenta un diagnóstico inicial que parte de considerar que el nuevo gobierno se encontró con empresas públicas mal administradas, sin coordinación ni estrategia comercial, fuertemente deficitarias y que no cumplían su compromiso con la sociedad. Ante este escenario, se señala que la nueva política gubernamental apunta a: 1) mejorar la gestión, con el objetivo de reducir al mínimo las transferencias provenientes de recursos fiscales; 2) aumentar el nivel de inversiones y mejorar la calidad de los servicios prestados; 3) centralizar la supervisión estratégica de las empresas; y 4) avanzar en una mayor transparencia y buen gobierno con el objetivo de incrementar la eficacia y prevenir hechos de corrupción. En paralelo, se avanzó en la centralización de determinadas funciones de control y seguimiento mediante la creación del Consejo de Supervisión Estratégica de las Empresas Públicas, en el marco de la Jefatura de Gabinete ${ }^{9}$.

Si nos detenemos en la cuestión presupuestaria, la tendencia entre de los últimos años ha expresado una sensible baja de las transferencias a las empresas públicas, pasando de representar un 1\% del PBI en 2015 a un $0,7 \%$ en 2016, además de estimarse en $0,5 \%$ para 2017 (JEFATURA DE GABINETE DE MINISTROS, 2017). Con la crisis cambiaria y

\footnotetext{
${ }^{9}$ El énfasis en la institucionalización de una instancia de coordinación y/o control, en vistas a la instauración de un modelo centralizado de gestión de las empresas públicas estatales, es una de las medidas que por lo general se impulsa desde los organismos internacionales; al respecto, véase por ejemplo Moreno de Acevedo Sánchez (2016).
} 
financiera de 2018 y la profundización de las políticas de ajuste fiscal, este énfasis se ha acentuado, especialmente en torno a la limitación de los subsidios destinados a los servicios públicos. En un sentido similar, se ha fijado el compromiso de llevar las transferencias a las empresas no relacionadas con la prestación de servicios públicos del 0,1\% del PBI en 2017 hasta casi cero en el 2021, lo cual se expresa en el Memorándum de Politicas Económicas y Financieras que fija los lineamientos del reciente acuerdo de tipo stand-by entre la Argentina y el Fondo Monetario Internacional. La política de ajuste también se refleja en una continua tendencia a la baja de la cantidad de empleo de las empresas públicas, estimándose aproximadamente 4.500 trabajadores despedidos durante el período diciembre 2015-mayo 2018 (CENTRO DE ECONOMÍA POLÍTICA ARGENTINA, 2018).

\subsection{CORPORATIZACIÓN NEOLIBERAL Y EL BUEN GOBIERNO DE LAS EMPRESAS PÚBLICAS ARGENTINAS}

Al nivel de la gestión de las empresas públicas, las actuales autoridades han tendido a ponderar positivamente las recomendaciones de políticas para el sector emitidas desde diferentes organismos internacionales ${ }^{10}$. Aunque éstos postulan los programas de privatización como un política pertinente en ciertos contextos (MORALES; GENDRON; GUÉNIN-PARACINI, 2014; ZACUNE, 2013), en los últimos años han ido prescribiendo en paralelo una orientación que pone el eje central en la idea de gobierno corporativo de las empresas públicas, entre las que sobresalen los estudios y propuestas de políticas enfocadas en países de América Latina (BANCO MUNDIAL, 2014; BERNAL et al., 2012; CORPORACIÓN ANDINA DE FOMENTO, 2010) ${ }^{11}$. La propia adopción de esa noción expresa la tendencia hegemónica de trasladar conceptos y tecnologías del sector privado al

\footnotetext{
${ }^{10}$ Dada la coyuntura argentina actual, no está de más recordar que — de manera destacada en América Latinala reforma del Estado de fines del siglo XX fue promovida por los principales gobierno del occidente capitalista, apoyados a su vez por la acción de los organismos financieros internacionales como el Fondo Monetario Internacional y el Banco Mundial y los diversos programas de crédito condicionado (ANDERSON, 2003; EZCURRA, 1998; HARVEY, 2007). Thwaites Rey (2010, p. 26) señala precisamente que una "de las herramientas de [la] penetración neoliberal la constituyó la deuda externa. El extraordinario endeudamiento contraído en los años setenta se utilizó en las décadas siguientes como arma disciplinadora, de la mano de la receta de ajuste fiscal y achicamiento estatal del FMI y el Banco Mundial. Es precisamente por medio de la deuda (que exige refinanciamiento permanente) como se expresa el carácter subordinado de la globalización capitalista en la periferia". Sin embargo, siguiendo lo señalado por Vilas (2013), no debe desconocerse que, aunque los organismos internacionales fueron fuente de argumentos y recursos que apuntalaron la primacía del discurso neoliberal, las propias clases y fracciones dominantes locales coincidían por su propio interés con los programas de ajuste y de reforma estatal.

${ }^{11}$ Ocasionalmente se utilizan expresiones como buen gobierno o buenas prácticas para referirse a este tipo de recomendaciones de políticas, aunque no suponen diferencias sustanciales con lo aquí indicado.
}

REAd | Porto Alegre - Vol. 25 - No 2 - Maio / Agosto 2019 - p. 63-95 
público como forma de acrecentar la eficiencia y transparencia: la idea de gobierno corporativo - entendido como los principios y normas que regulan el funcionamiento de una empresa - surgió en el ámbito empresarial privado hace medio siglo y solo en los últimos lustros comenzó a utilizarse en referencia a entes estatales (DÍAZ ORTEGA, 2010; PORTALANZA, 2013).

Particularmente, en el marco de la pretensión de incorporar al Estado argentino como miembro pleno a la Organización para la Cooperación y el Desarrollo Económico (OCDE), el gobierno nacional ha tomado como guía sus propuestas de política para la gestión de las empresas públicas. La OCDE se destaca entre otros organismos por contar con una instancia interna dedicada exclusivamente a reflexionar y proponer políticas para el sector, el Grupo de Trabajo sobre Propiedad Estatal y Prácticas de Privatización. Adicionalmente, se trata de un organismo cuyos antecedentes resultan importantes en lo que se refiere a delinear distintas propuestas de políticas de reforma estatal durante el auge de las políticas de la NGP a fines del siglo pasado (HADJIISKY, 2017).

Con diversas ediciones previas — que datan de mediados de la década pasada -, la publicación titulada Directrices de la OCDE sobre el Gobierno Corporativo de las Empresas Públicas (OCDE, 2016, p. 7; en adelante, las Directrices) se presenta como un documento de referencia sobre la cuestión. La intención declarada es la de enumerar una serie de recomendaciones acordadas internacionalmente con el fin de que las empresas públicas operen con eficiencia y transparencia, puedan rendir cuentas y se eviten los inconvenientes característicos de lo que señalan como la falta o el exceso de intervención estatal. De manera destacada, se declara que las Directrices deben aplicarse, cuando sea posible, en conjunto con los lineamientos propuestos para las empresas privadas de la propia OCDE, con los que resultan compatibles. La existencia de un 'buen gobierno' de las empresas públicas es presentada como "fundamental para la existencia de mercados eficientes y libres tanto en el ámbito nacional como internacional" (OCDE, 2016, p. 7) y como base para el crecimiento económico.

Los objetivos de las Directrices son los siguientes: “(i) profesionalizar al Estado como propietario; (ii) hacer que las empresas públicas funcionen con una eficacia, transparencia y responsabilidad similar a las de las empresas privadas que aplican buenas prácticas; y (iii) velar por que la competencia entre las empresas públicas y las privadas, allí donde exista, se desarrolle en igualdad de condiciones" (OCDE, 2016, p. 11). Por otra parte, aunque no se define qué áreas deben ser públicas o privadas, sí se busca que las recomendaciones 
presentadas sirvan para que, en el caso de decidir privatizar una empresa pública, se haga en las mejores condiciones posibles.

Citando a la OCDE como fuente de la política a desplegar, la Jefatura de Gabinete de Ministros emitió la Decisión Administrativa No85/2018, mediante la cual aprueba un documento denominado Lineamientos de Buen Gobierno para Empresas de Participación Estatal Mayoritaria de Argentina (JEFATURA DE GABINETE DE MINISTROS, 2018; en adelante, los Lineamientos). Entre sus fundamentos se señala que, ante la incorporación y creación de empresas públicas acaecido de 2003, se constata que "la gestión de dichas empresas y sociedades no se caracterizó por el seguimiento de prácticas de buen gobierno corporativo ni por promover la utilización sustentable y transparente de los recursos públicos". Como consecuencia, se afirma que la gestión ineficiente generó déficits operacionales significativos en las empresas, requiriendo la transferencia de importantes aportes presupuestarios. Mediante el contenido de los Lineamientos se fijan las expectativas sobre cómo se espera que las empresas estatales se organicen y gestionen, favoreciendo la prestación de un mejor y más transparente servicio para los ciudadanos y el fortalecimiento de la sustentabilidad e integridad de las entidades alcanzadas.

En este sentido, los Lineamientos aportan una mirada general sobre los objetivos para el sector fijados desde el gobierno nacional, dejando a cada empresa la adopción del diseño institucional que resulte más conveniente para tales fines. Para esto se definen una serie de principios, lineamientos y aplicaciones prácticas (correspondientes a cada lineamiento), los cuales conforman de conjunto el núcleo de la política propuesta.

En la primera sección del documento se incluyen, como base conceptual, los siguientes 'seis principios de buen gobierno' para las empresas estatales: (a) 'eficiencia' - en términos de la maximización de los recursos transferidos para la producción de mejores bienes y servicios a un costo acorde a los valores de mercado.; (b) 'transparencia' - mediante la publicación de información financiera y no financiera vinculada a su desempeño; (c) 'integridad' - apostando a la prevención y castigo del fraude, en el marco del desarrollo de políticas anticorrupción; (d) 'generación de valor' - se promueve la maximización del impacto de las empresas estatales en la economía, comprendiendo la generación de valor social y económico a lo largo de toda la cadena del negocio; (e) 'estándar de empresa listada' - se espera que las empresas adopten estándares de gobierno corporativo alineados con los de empresas que cotizan en la bolsa de valores; (f) 'roles diferenciados' - se propone diferenciar los roles del Estado como accionista, como formulador de políticas y como regulador, aun 
cuando dependan de un mismo organismo (JEFATURA DE GABINETE DE MINISTROS, 2018).

En cuanto a los 'siete lineamientos' propuestos, se desagregan en cada caso cada una serie de medidas que retoman, de manera transversal y en diferentes grados, los principios de buen gobierno mencionados anteriormente. En cualquier caso, a pesar de cada lineamiento puede tratar asuntos disímiles, puede resultar útil sopesarlos a partir de su agrupamiento en al menos tres áreas temáticas o tipo de cuestiones que abordan. Un primer grupo (lineamientos 1, 2 y 3) se corresponde con determinadas medidas que apuntan al mejoramiento de la transparencia y el acceso a la información pública, con vistas a reforzar la rendición de cuentas y el escrutinio público; el establecimiento de medidas contra la corrupción y un régimen de integridad; y el desarrollo de políticas de sustentabilidad de tipo ambiental, social, institucional y de diversidad. En segundo lugar, el lineamiento 4 se encarga de identificar algunos criterios al momento de evaluar el desempeño económico. En este caso, se prioriza: el establecimiento de una gestión basada en resultados, en función de un plan estratégico vinculado al presupuesto; la rendición de cuentas sobre la ejecución presupuestaria, los recursos insumidos y las metas alcanzadas; el establecimiento de incentivos, en principio los de tipo moral pero sin excluir los pecuniarios, dejando en manos de la conducción de la empresa el establecimiento de una política en este ámbito; el impulso al cobro de deudas a otras empresas estatales; y la coordinación en el manejo presupuestario respecto con las autoridades ministeriales. Finalmente, un tercer grupo (lineamientos 5, 6 y 7) apunta a favorecer la profesionalización de la alta gerencia, especialmente en términos técnicos, con énfasis en su evaluación a partir de sus resultados medidos es términos de eficacia y sustentabilidad; el establecimientos de una política de compras y abastecimiento que asuma un carácter estratégico, transparente y sujeta a evaluaciones de desempeño; y la intensificación de la relevancia de las instancias de auditoría y control, similares a las empresas privadas (JEFATURA DE GABINETE DE MINISTROS, 2018).

Por lo demás, en una revisión reciente la propia OCDE valora positivamente los pasos dados por el gobierno argentino en este ámbito. Entre otros aspectos, se destacan los esfuerzos por limitar las transferencias fiscales a las empresas públicas y en el hecho de que los precios de los servicios públicos han ido convergiendo cada vez en mayor medida con los precios de mercado. Los reparos vienen dados por la necesidad de crear marcos institucionales que hagan que esas tendencias puedan perdurar en el tiempo: por ejemplo, mediante un modelo de propiedad claro, con clara separación de roles; el mejoramiento de la 
alta dirección de las empresas y un aumento de su autonomía; y mejores políticas de transparencia y acceso a la información (OCDE, 2018).

En definitiva, la tendencia de las políticas implementadas, así como de las orientaciones propuestas durante el período 2015-2018, procuran ubicar en el centro de la discusión las formas de gestión de las empresas públicas argentinas y, en general, el rol que éstas desempeñan en el contexto económico. En este sentido, se indican medidas que, sin llegar a cuestionar explícitamente la propiedad pública, se emparentan con la perspectiva de la corporatización neoliberal que hemos delineado. Por lo demás, esto no quita que, en una coyuntura propicia, se pretendan dar avances en línea a las políticas de privatización clásicas. Con ese fin, una reorganización de las empresas públicas en los términos planteados puede resultar favorable en vistas a un futuro traspaso al sector privado.

\section{CONSIDERACIONES FINALES}

El análisis de las tendencias recientes de las políticas para las empresas públicas en el caso argentino, aunque incipientes en algunos casos, permiten identificar ciertos ejes fundamentales en torno a los cuales se organiza la acción estatal. De manera destacada, emerge con fuerza las vinculaciones de dichas políticas con los lineamientos típicos de los procesos de corporatización neoliberal. De manera resumida, podemos mencionar los siguientes elementos que incentivan esa interpretación: priorización de la eficiencia ligada al resultado financiero positivo, sin depender — hasta donde sea posible — de las transferencias de recursos fiscales; en base a lo anterior, la limitación presupuestaria tiende a favorecer la premisa de que "los precios reflejen los costos", como una mercancía más en el mercado; se revaloriza un saber técnico que, bajo el epíteto de la profesionalización, se lo ubica aislado de lo que se considera la intromisión de intereses políticos; se debilita la idea de las empresas estatales como un instrumento de política pública, tendiendo a asimilar su funcionamiento y objetivos al de una empresa privada; la compartimentalización respecto a otras empresas y organismos públicos tiende a debilitar la planificación y coordinación estatal en torno a los objetivos de interés general — como un mayor acceso a los servicios públicos, el sostenimiento del empleo o la promoción de determinado sector económico considerado estratégico; el "tratamiento igualitario" de accionistas minoritarios y respecto a otros actores en el mercado implica la apertura de nuevos ámbitos de competencia con empresas privadas.

En este escenario, un elemento que no se expresa totalmente - salvo algunas excepciones - en la política llevada adelante es el relacionado con la autonomía gerencial de 
la empresa pública, persistiendo una fuerte subordinación a la conducción de las autoridades gubernamentales. Es posible aventurar que la actual situación de restricción y ajuste presupuestario tienda a priorizar el objetivo de reducción del déficit fiscal por sobre otras consideraciones u objetivos de política pública. Con ese fin, la primacía de la autoridad gubernamental puede resultar una manera más efectiva de alcanzar los objetivos fijados en torno a la baja o la eliminación de las transferencias de recursos fiscales.

En cualquier caso, a partir de este breve recorrido, podemos afirmar la existencia de una propensión a asimilar el funcionamiento de las empresas públicas al de las empresas privadas en vistas a la ampliación de las lógicas de mercado, como una forma de profundizar su corporatización en el sentido neoliberal. En este escenario, la permanencia de la titularidad pública y la ausencia de un programa amplio de privatizaciones tradicionales no parece implicar, por lo demás, la inexistencia de una política esencialmente ligada al neoliberalismo. Particularmente, se ha pretendido esbozar una trayectoria de las orientaciones de políticas para las empresas públicas —especialmente las que se hallan en curso de implementación en la que se han podido identificar diversas conexiones con la perspectiva del neoliberalismo y los postulados del paradigma de la NGP.

Dado que las políticas analizadas se encuentran en un estado inicial de su desarrollo, queda planteado el interrogante de cómo evolucionarán en la práctica en el futuro cercano y cuáles serán sus implicancias a nivel social y económico. Especialmente, surge la pregunta si la profundización de este tipo de políticas afectará el acceso a los servicios públicos básicos y/o si se limitará aún más la intervención estatal directa en sectores hasta ahora considerados estratégicos para el desarrollo económico y social. Además, en torno a la evaluación de las funciones estatales y sus cambios recientes cabe preguntarse cómo se relacionan las políticas de corporatización neoliberal con otras políticas concurrentes - como la tendencia a la externalización o al desarrollo de asociaciones público-privadas — en la consideración general del programa gubernamental. Finalmente, queda pendiente también las reflexiones relacionadas a las alternativas públicas que se pueden vislumbrar frente a la política actual; especialmente aquellas que supongan una sustracción relativa de la dinámica mercantil, una ampliación de los ámbitos democráticos de funcionamiento y que reinstalen el debate sobre el desarrollo económico y el bienestar social. 


\section{REFERENCIAS}

ANDERSON, P. Neoliberalismo: un balance provisorio. In: SADER, E.; GENTILE, P. (Eds.). La trama del Neoliberalismo: mercado, crisis y exclusión social. Buenos Aires: CLACSO, 2003. p. 11-25.

ARZA, C. El impacto social de las privatizaciones: el caso de los servicios públicos domiciliarios. Buenos Aires: FLACSO - Sede Argentina, 2002.

AZPIAZU, D.; BASUALDO, E. Las privatizaciones en la Argentina. Genesis, desarrollo y principales impactos estructurales. In: PETRAS, J.; VELTMEYER, H. (Eds.). Las privatizaciones y la desnacionalización de América Latina. Buenos Aires: Prometeo Libros, 2004. p. 55-112.

AZPIAZU, D.; CASTRO, J. E. Aguas públicas: Lecciones desde Buenos Aires. In: PIGEON, M. et al. (Eds.). Remunicipalización: El retorno del agua a manos públicas. Ámsterdam: Transnational Institute, 2013.

AZPIAZU, D.; SCHORR, M. Crónica de una sumisión anunciada: las renegociaciones con las empresas privatizadas bajo la administración Duhalde. Buenos Aires: Siglo Veintiuno Editores Argentina, 2003.

BAKKER, K. The "Commons" Versus the "Commodity": Alter-globalization, Antiprivatization and the Human Right to Water in the Global South. Antipode, v. 39, n. 3, p. 430-455, jun. 2007.

BANCO MUNDIAL. Tendencias del gobierno corporativo de las empresas públicas en América Latina. Tendencias y casos de países. Washington DC: Banco Mundial, 2014. BELINI, C.; ROUGIER, M. EI Estado empresario en la industria argentina: conformación y crisis. Buenos Aires: Manantial, 2008.

BERNAL, A. et al. Gobierno Corporativo en América Latina. Importancia para las Empresas de Propiedad Estatal. Caracas: CAF, 2012.

BERNIER, L. Public enterprises as policy instruments: the importance of public entrepreneurship. Journal of Economic Policy Reform, v. 17, n. 3, p. 253-266, 3 jul. 2014. BLUTMAN, G. Ensayos truncos de reforma y modernización del Estado en Argentina. In: MADUREIRA, C.; ASENSIO, M. (Eds.). Handbook de Administração Pública. Lisboa: INA Editora, 2013. p. 257-273. 
BLUTMAN, G.; CAO, H. Hoja de ruta sobre reforma y modernización del Estado.

APORTES para el Estado y la Administración Gubernamental, v. 18, n. 30, p. 15-42, dez. 2012.

BONNET, A. Políticas neoliberales y lucha de clases. In: BONEFELD, W. et al. (Eds.).

Marxismo abierto: una visión europea y latinoamericana. Buenos Aires, Herramienta;

Puebla: Benemérita Universidad Autónoma de Puebla, 2007. v. II.

BONNET, A.; PIVA, A. El estado en el kirchnerismo. Un análisis de los cambios en la forma de estado a partir de la crisis de 2001. In: GRIGERA, J. (Ed.). Argentina: después de la convertibilidad (2002-2011). Colección Bitácora argentina. Buenos Aires: Imago Mundi, 2013. p. 3-31.

BRESSER PEREIRA, L. C. Estado y mercado en el Nuevo Desarrollismo. Nueva Sociedad, n. 210, p. 110-125, ago. 2007.

BRUTON, G. D. et al. State-owned enterprises around the world as hybrid organizations.

Academy of Management Perspectives, v. 29, n. 1, p. 92-114, 1 fev. 2015.

CASTAÑEDA RODRÍGUEZ, V. M.; DÍAZ BAUTISTA, O. El Consenso de Washington: algunas implicaciones para América Latina. Apuntes del CENES, v. 36, n. 63, p. 15-45, 2017.

8 fev. 2017.

CENTRO DE ECONOMÍA POLÍTICA ARGENTINA. El "saneamiento" de las empresas estatales. Buenos Aires: Centro de Economía Política Argentina, jul. 2018. Disponoble en: https://gallery.mailchimp.com/e9c6f62a4dc825f6a9dab4e88/files/fb0e6d58-d878-4d96-a478af2f821f6280/El_saneamiento_de_empresas_p\%C3\%BAblicas_CEPA.pdf. Acceso en: 24 ago. 2018.

CHAVEZ, D.; TORRES, S. Introducción: empresas públicas y desarrollo en Uruguay, América Latina y el mundo. In: CHAVEZ, D.; TORRES, S. (Eds.). La reinvención del Estado: empresas públicas y desarrollo en Uruguay, América Latina y el mundo. Montevideo: Transnational Institute, 2013. p. 13-28.

CHESNAIS, F. Introducción general. In: CHESNAIS, F. (Ed.). La mundialización

financiera: génesis, costo y desafíos. Buenos Aires: Losada, 2001. p. 19-43.

CHRISTENSEN, T.; LÆGREID, P. Post-NPM Reforms: Whole of Government Approaches as a New Trend. In: GROENEVELD, S.; VAN DE WALLE, S. (Eds.). Research in Public Policy Analysis and Management. [s. 1.] Emerald Group Publishing Limited, 2011. p. 1124. 
CHRISTIANSEN, H. The Size and Composition of the SOE Sector in OECD Countries. Paris: [s.n.]. Disponible en: https://www.oecd-ilibrary.org/governance/the-size-andcomposition-of-the-soe-sector-in-oecd-countries 5kg54cwps0s3-en. Accesso en: 21 ene. 2018.

\section{CORPORACIÓN ANDINA DE FOMENTO. Lineamientos para el Buen Gobierno}

Corporativo de las Empresas del Estado. Caracas: CAF, 2010.

DAN, S. et al. Effects of privatization and agencification on citizens and citizenship: an international comparison. [s. 1.] COCOPS, 2012.

DEVLIN, R. Las privatizaciones y el bienestar social. Revista de la CEPAL, n. 49, p. 155181, abr. 1993.

DÍAZ ORTEGA, E. Gobierno corporativo: lo que todo empresario debe saber. Caracas: CAF, 2010.

DIÉGUEZ, G.; VALSANGIACOMO, A. El péndulo del mercado al Estado: ¿qué pasó con las empresas públicas en la última década en Argentina? Buenos Aires: CIPPEC, nov. 2016. DUMÉNIL, G.; LÉVY, D. Une théorie marxiste du néolibéralisme. Actuel Marx, v. 40, n. 2, p. 24-38, 2006.

ESTRIN, S. et al. Home country institutions and the internationalization of state owned enterprises: A cross-country analysis. Journal of World Business, v. 51, n. 2, p. 294-307, fev. 2016.

EZCURRA, A. M. ¿Qué es el neoliberalismo? Evolución y límites de un modelo excluyente. Buenos Aires: Lugar Editorial, 1998.

FÉLIZ, M. Argentina 2011-2016: ¿De la crisis del neodesarrollo a su radicalización conservadora? Luchas sociales, proyectos de desarrollo y alternativas populares. Lutas Sociais, v. 20, n. 37, p. 72-85, 2016.

FLEURY, S. Reforma del Estado en América Latina. ¿Hacia dónde? Nueva Sociedad, n. 160, p. 58-80, abr. 1999.

FLORIO, M. Repensar la empresa pública: la nueva agenda de investigación. In: CHAVEZ, D.; TORRES, S. (Eds.). La reinvención del Estado: empresas públicas y desarrollo en Uruguay, América Latina y el mundo. Montevideo: Transnational Institute, 2013. p. 23-46. FLORIO, M. The return of public enterprise. Milano: CSIL - Center for Industrial Studies, 2014a.

FLORIO, M. Empresas públicas contemporáneas en una perspectiva global: teoría y evidencia. Revista del CLAD Reforma y Democracia, n. 60, p. 59-102, out. 2014b. 
FLYVBJERG, B. Cinco malentendidos acerca de la investigación mediante los estudios de caso. Reis, n. 106, p. 33-62, 2004.

GUAJARDO, G.; LABRADOR, A. (EDS.). La empresa pública en México y en América Latina: entre el mercado y el Estado. México: Universidad Nacional Autónoma de México, Instituto Nacional de Administración Pública, 2015.

GUAJARDO SOTO, G. La empresa pública y sus definiciones en el largo plazo. In: GUAJARDO, G.; LABRADOR, A. (Eds.). La empresa pública en México y en América Latina: entre el mercado y el Estado. México: Universidad Nacional Autónoma de México, Instituto Nacional de Administración Pública, 2015. p. 23-36.

GUERRERO, O. El mito del nuevo managemen público. In: GUERRERO, O. (Ed.). .

Gerencia pública: una aproximación plural. México: UNAM, Dirección General de Publicaciones y Fomento Editorial, 2004. p. 67-137.

GUERRERO, O. El fin de la nueva gerencia pública. Estado, Gobierno, Gestión Pública Revista Chilena de Administración Pública, n. 13, p. 5-22, jun. 2009.

HADJIISKY, M. Explorando una conversión. La Nueva Gestión Pública en la Organización para la Cooperación y el Desarrollo Económico (OCDE), entre 1970 y 1980. Estudios

Sociales del Estado, v. 3, n. 5, p. 55-98, primer semestre de 2017.

HALL, D. Public and Private Sector Efficiency. [s. 1.] EPSU, 2014.

HARVEY, D. El “nuevo" imperialismo: acumulación por desposesión. In: Socialist Register 2004. Buenos Aires: CLACSO, 2005. p. 99-129.

HARVEY, D. Breve historia del neoliberalismo. Madrid: Akal, 2007.

HERNÁNDEZ DE COS, P. Empresa pública, privatización y eficiencia: Estudios

Económicos. Madrid: Banco de España, 2004.

HOOD, C. A public management for all seasons. Public Administration, v. 69, p. 3-19, Spring 1991.

JEFATURA DE GABINETE DE MINISTROS. Empresas públicas para el crecimiento:

Carta de Jefatura de Gabinete. Buenos Aires: Jefatura de Gabinete de Ministros, abr. 2017. JEFATURA DE GABINETE DE MINISTROS. Lineamientos de Buen Gobierno para Empresas de Participación Estatal Mayoritaria de Argentina. Buenos Aires: Jefatura de Gabinete de Ministros, fev. 2018.

JIMÉNEZ MARTÍN, C.; PUELLO-SOCARRÁS, J. F. Las disputas en torno a la común. Experiencias comunales de gobierno desde abajo como alternativas contrahegemónicas. In: JIMÉNEZ MARTÍN, C. et al. (Eds.). Lo Común: alternativas políticas desde la diversidad. 
Estudios Técnicos para la Construcción de la Paz. Bogotá: Planeta Paz, OXFAM, 2017. p. $29-50$.

KATZ, C. ¿Qué es el neodesarrollismo? Una visión crítica. Argentina y Brasil. Serviço Social \& Sociedade, n. 122, p. 224-249, jun. 2015.

LECHNER, N. El debate sobre Estado y mercado. Estudios Públicos, n. 47, p. 235-247, 1992.

LÓPEZ, A. La Nueva Gestión Pública: algunas precisiones para su abordaje conceptual:

Serie I: Desarrollo Institucional y Reforma del Estado. Buenos Aires: Instituto Nacional de la Administración Pública - Dirección de Estudios e Información, 2002.

MAGDAHL, J. E. From privatisation to corporatisation. Exploring the strategic shift in neoliberal policy on urban water services. Oslo: FIVAS, 2012.

MAZZUCATO, M. The entrepreneurial state. London: Demos, 2011.

MCCARTHY, J. Commons as counterhegemonic projects. Capitalism Nature Socialism, v. 16, n. 1, p. 9-24, mar. 2005.

MCDONALD, D. A. La ambigüedad de lo público y los numerosos significados de la corporatización. In: MCDONALD, D. A. (Ed.). Servicios públicos en el Sur global: mirada crítica a nuevas formas de gestión. Madrid: Clave Intelectual, 2015. p. 9-46.

MCDONALD, D. A. To corporatize or not to corporatize (and if so, how?). Utilities Policy, v. 40, p. 107-114, jun. 2016.

MCDONALD, D. A. Remunicipalization: The future of water services? Geoforum, v. 91, p. 47-56, maio 2018.

MCDONALD, D. A.; RUITERS, G. (EDS.). Alternativas a la privatización: la provisión de servicios públicos esenciales en los países del sur. Barcelona: Icaria, 2013.

MILLWARD, R. Public enterprise in the modern western world: an historical analysis.

Annals of Public and Cooperative Economics, v. 82, n. 4, p. 375-398, dez. 2011.

MONTES, M. El rol de las empresas del Estado en el desarrollo industrial. In: CHAVEZ, D.;

TORRES, S. (Eds.). . La reinvención del Estado: empresas públicas y desarrollo en Uruguay, América Latina y el mundo. Montevideo: Transnational Institute, 2013. p. 47-58.

MORALES, J.; GENDRON, Y.; GUÉNIN-PARACINI, H. State privatization and the unrelenting expansion of neoliberalism: The case of the Greek financial crisis. Critical Perspectives on Accounting, v. 25, n. 6, p. 423-445, set. 2014.

MORENO DE ACEVEDO SÁNCHEZ, E. Gestión de empresas públicas: las ventajas de los modelos centralizados, Instituciones para el Desarrollo. División de Capacidad Institucional del Estado. Washington, D.C.: Banco Interamericano de Desarrollo, mai. 2016. 
MOYNIHAN, D. P. Ambiguity in policy lessons: the agencification experience. Public Administration, v. 84, n. 4, p. 1029-1050, dez. 2006.

ORGANIZACIÓN PARA LA COOPERACIÓN Y EL DESARROLLO. Directrices de la OCDE sobre el Gobierno Corporativo de las Empresas Públicas. Paris: Éditions OCDE, 2016 .

OCDE, [ORGANIZACIÓN PARA LA COOPERACIÓN Y EL DESARROLLO. OECD

Review of the Corporate Governance of State-Owned Enterprises: Argentina. [s. 1.] OECD, 2018.

OSTROM, E. Beyond Markets and States: Polycentric Governance of Complex Economic Systems. American Economic Review, n. 100, p. 641-672, jun. 2010.

OSZLAK, O. De menor a mejor. El desafío de la segunda reforma del Estado. Nueva Sociedad, n. 160, p. 81-100, abr. 1999.

OSZLAK, O. El mito del estado mínimo: una década de reforma estatal en la Argentina.

Desarrollo Económico, v. 42, n. 168, p. 519, jan. 2003.

OSZLAK, O.; O’DONNELL, G. A. Estado y políticas estatales en América Latina: hacia una estrategia de investigación. REDES, v. 2, n. 4, p. 99-128, set. 1995.

PÉREZ, V. El dilema de los híbridos sociales como alternativa de producción. El caso del transporte ferroviario de pasajeros del área metropolitana de Buenos Aires (2003-2015).

Perspectivas de Políticas Públicas, n. 10, p. 121-141, 2016.

PÉREZ, V.; ROCCA, M. V. Estado y servicios públicos en la posconvertibilidad (20032015): ¿qué hubo de nuevo en la participación estatal? Temas y Debates, v. 21, n. 33, p. 6388, jun. 2017.

PIGEON, M. et al. (EDS.). Remunicipalización: el retorno del agua a manos públicas. Ámsterdam: Transnational Institute, 2013.

POLLITT, C.; BOUCKAERT, G. Public management reform: a comparative analysis: new public management, governance, and the neo-Weberian state. 3rd ed ed. Oxford; New York: Oxford University Press, 2011.

PORTALANZA, A. Gobierno corporativo: una aproximación teórica. Saber, Ciencia y Libertad, v. 8, n. 1, p. 117-127, 2013.

PRATS I CATALÁ, J. Reforma del Estado y Cooperación para la Reforma del Estado en América Latina. Nueva Sociedad, n. 160, p. 110-125, abr. 1999.

PUELLO-SOCARRÁS, J. F. Neoliberalismo, antineoliberalismo, nuevo neoliberalismo. Episodios y trayectorias económico-políticas sudamericanas (1973-2015). In: ROJAS 
VILLAGRA, L. (Ed.). Neoliberalismo en América Latina: crisis, tendencias y alternativas. Asunción: CLACSO, 2015. p. 18-42.

RE CRESPO, S.; SCHCLAREK CURUTCHET, A.; TORRES, L. A. Empresas del Estado: Errores del pasado, soluciones a futuro. [s.1.] CIPPES (Centro de Investigaciones Participativas en Políticas Económicas y Sociales), 27 dez. 2011.

REGALSKY, A. M.; ROUGIER, M. (EDS.). Introducción. In: Los derroteros del estado empresario en la Argentina: siglo XX. Sáenz Peña, Provincia de Buenos Aires: EDUNTREF, 2015. p. 7-30.

ROCCA, M. V. Continuidades y rupturas en el servicio de agua potable y saneamiento en el Área Metropolitana de Buenos Aires (1993-2010). Revista Electrónica del Instituto de Investigaciones “Ambrosio L. Gioja”, v. VI, n. 8, p. 146-173, Invierno 2012.

SABBATELLA, I. M. La política petrolera de la posconvertibilidad: de la herencia neoliberal a la expropiación de YPF. Argumentos - Revista de crítica social, n. 14, p. 149-180, 2012. SADER, E. Refundar el Estado: Posneoliberalismo en América Latina. Buenos Aires: CLACSO, CTA, 2008.

SALGADO, E. Teoría de costos de transacción: una breve reseña. Cuadernos de Administración, v. 16, n. 26, p. 61-78, dez. 2003.

SCHCLAREK CURUTCHET, A. Razones teóricas para la existencia de las empresas del Estado. In: CHAVEZ, D.; TORRES, S. (Eds.). La reinvención del Estado. Empresas públicas y desarrollo en Uruguay, América Latina y el mundo. Montevideo:

Transnational Institute, 2013. p. 81-90.

SIDICARO, R. La crisis del estado: y los actores políticos y socioeconómicos en la Argentina (1989 - 2001). Buenos Aires: EUDEBA, 2003.

STEFANONI, P. Posneoliberalismo cuesta arriba. Los modelos de Venezuela, Bolivia y Ecuador en debate. Nueva Sociedad, n. 239, p. 51-64, jun. 2012.

SULEIMAN, E. ¿Es Max Weber realmente irrelevante? Gestión y Análisis de Políticas Públicas, n. 17-18, 20 mai. 2011.

THWAITES REY, M. La (des)ilusión privatista: el experimento neoliberal en la Argentina. Buenos Aires: Libros del Rojas, Universidad de Buenos Aires, Centro Cultural Rector Ricardo Rojas: EUDEBA, 2003.

THWAITES REY, M. Después de la globalización neoliberal: ¿Qué Estado en América Latina?" en OSAL (Buenos Aires: CLACSO) Año XI, N 27, abril. OSAL, v. XI, n. 27, p. 19-43, abr. 2010. 
THWAITES REY, M. Estado y empresas públicas en América Latina: Historia y desafíos actuales. In: CORTÉS-RAMOS, A.; ALPÍZAR, F.; CASCANTE, M. J. (Eds.). . Estado, Empresas Públicas y Desarrollo. San José: CIEP-Universidad de Costa Rica, Transnational Institute, 2016. p. 224-256.

THWAITES REY, M.; LÓPEZ, A. (EDS.). Entre tecnócratas globalizados y políticos clientelistas: derrotero del ajuste neoliberal en el Estado argentino. Buenos Aires: Prometeo, 2005.

TONINELLI, P. A. The Rise and Fall of Public Enterprise: The Framework. In: TONINELLI, P. A. (Ed.). The Rise and Fall of State-Owned Enterprise in the Western World. Cambridge: Cambridge University Press, 2000. p. 3-24.

TONINELLI, P. A. From private to public to private again: a long-term perspective on nationalization. Análise Social, v. XLIII (4. $\left.{ }^{\circ}\right)$, n. 189, p. 675-859, 2008.

VALLES, M. S. Técnicas cualitativas de investigación social: reflexión metodológica y práctica profesional. Madrid: Síntesis, 1997.

VAN THIEL, S. Comparing Agencies across Countries. In: VERHOEST, K. et al. (Eds.).

Government Agencies. London: Palgrave Macmillan UK, 2012. p. 18-26.

VICHER, D. Derechos de propiedad y costos de transacción en administración pública. Análisis, n. 5, p. 102-126, abr. 2010.

VILAS, C. M. América Latina: Estado y sociedad a partir de la crisis - un ensayo de síntesis. México, D.F: Centro de Investigaciones Interdisciplinarias en Humanidades UNAM, 1991.

VILAS, C. M. La reforma del Estado como cuestión política. Política y Cultura, n. 8, p. 147-185, primavera 1997.

VILAS, C. M. ¿Más allá del “Consenso de Washington”? Un enfoque desde la política de algunas propuestas del Banco Mundial sobre reforma institucional. Revista del CLAD Reforma y Democracia, n. 18, out. 2000.

VILAS, C. M. El síndrome de Pantaleón. Política y administración en la reforma del Estado y la gestión de gobierno. In: SCHWEINHEIM, G. (Ed.). Estado y Administración Pública. Buenos Aires: Asociación Argentina de Estudios sobre Administración Pública, 2009.

VILAS, C. M. El Banco Mundial y la reforma del Estado en América Latina:

Fundamentos teóricos y prescripciones políticas, 2013. Disponble en:

http://cmvilas.com.ar/index.php/articulos/14-es-tado-y-democracia/110-el-banco-mundial-yla-reforma-del-esta-do-en-america-latina-fundamentos-teoricos-y-prescripciones-politi-cas. Acceso en: 2 feb. 2018. 
VOSZKA, É. Nationalization or ptivatization? The fragmentation of the mainstrem. Annals of Public and Cooperative Economics, v. 88, n. 1, p. 91-120, mar. 2017.

ZACUNE, J. Privatizando Europa. La crisis como tapadera para consolidar el neoliberalismo. Ámsterdam: Transnational Institute, maio 2013.

ZURBRIGGEN, C. La "falacia tecnocrática" y la reforma del Estado. A 10 años del Informe del Banco Mundial. Nueva Sociedad, n. 210, p. 156-172, ago. 2007. 